Proc. Indian Acad. Sci. (Earth. Planet. Sci.), Vol. 89, Number 2, July 1980, pp. 215-230.

(C) Printed in India.

\title{
Some thermodynamical and microphysical aspects of monsoon clouds
}

\author{
A MARY SELVAM, A S RAMACHANDRA MURTY, \\ R VIJAYAKUMAR, S K PAUL, G K MANOHAR, \\ R S REDDY, B K MUKHERJEE and Bh. V. RAMANA MURTY \\ Indian Institute of Tropical Meteorology, Poona 411 005, India
}

MS received 2 June 1979 ; revised 1 April 1980

\begin{abstract}
The thermodynamical and microphysical characteristics of monsoon clouds in the Poona, Bombay and Rihand regions were investigated using extensive aircraft in-cloud observations. The number of clouds sampled at Poona, Bombay and Rihand is 2199,169 and 104 respectively.

The temperatures inside the cloud are colder than its environment at Poona and Rihand. The maximum difference is about $3^{\circ} \mathrm{C}$ at the cloud base level and the difference decreased with height. At Bombay the difference is less than $1^{\circ} \mathrm{C}$ and at some levels the temperatures inside the cloud are warmer than its environment.

The lapse rates of temperatures inside the cloud are slightly less than those in the immediate environment of the cloud. The environmental lapse rates are rearly equal to the saturated adiabatic value.

The positive increments in liquid water content (LWC) are associated with the increments in temperature inside the cloud. Similarly positive increments in temperatures inside the cloud are associated with the increments in temperature of its immediate environment at the same level or the layer immediately above.

The maximum cloud lengths observed at Poona and Bombay respectively are 14 and $3 \mathrm{~km}$. The horizontal cross-section of LWC showed a maximum numter of 13 peaks in clouds at Poona while only 7 peaks were observed at Bombay. The location of maximum LWC in the horizontal cross-section is more or less at the centre of the cloud. The LWC profile showed an increase with height from the base of the cloud at Poona and Bombay. There is no marked variation of LWC with height at Rihand.

The total droplet concentration at different altitudes at Poona and Bombay is in the range $28-82 \mathrm{~cm}^{-3}$. The size distribution of cloud droplets experienced a broadening effect with increase in height from the cloud base at Poona. The broadening effect at Bombay is not as marked as that at Poona.
\end{abstract}

Keywords. Cloud liquid water content; adiabatic liquid water content; cloud droplet size distribution; lapse rate of temperature; monsoon clouds.

\section{Introduction}

The progress made in cloud madelling is very slow due to the deficiency in relating the present theories to scanty in-cloud measurements of microphysical and dynamical parameters (Simpson 1976). Even in regard to bulk properties such as cloud liquid water content and temperature profiles, there is insufficient obser- 
vational evidence as to how these properties vary during the life-time of a cloud to enable atmospheric physicists to make meaningful comparisons with the predicted values from the cloud models.

In-cloud measurements of the microphysical and dynamical parameters of warm clouds are more sparse than those in cold clouds. Particularly noteworthy of such limited observations are the measurements made in Australia (Warner $1969,1970,1973$ ). Such measurements in monsoon clouds could not be undertaken in India till recently due to the prohibitive cost of the instrumented aircraft fasility required for such programmes. As a part of the aerial cloud seeding experiments undertaken by the Indian Institute of Tropical Meteorology, Poona, systematic observations using a DC-3 instrumented aircraft could bo undertaken in several hundreds of monsoon clouds in a few regions in the country.

Observations on (i) cloud liquid water content (LWC), (ii) cloud droplet size distributions, (iii) cloud diameters, (iv) temperatures of the cloud and cloud-free air were made in the Poona, Bombay and Rihand regions during the summer monsoon seasons of 1973, 1974 and 1976. The total number of clouds sampled at Poona, Bombay and Rihand respectively is 2199,169 and 104 . Lapse rates of the environment and cloud-air, adiabatic liquid water content $\left(W_{0}\right)$ are also computed using the aircraft and radiosonde temperature data. The results of the study are presented below.

\section{Meteorological conditions}

A brief summary of the meteorological conditions during the summer monsoon (June-September) in the three regions is given below.

\subsection{Bombay}

Situated on the west coast and large influx of moisture is brought inland by the air masses coming from the Arabian Sea. Westerly to southwesterly air flow prevails in the lower troposphere. Heavy precipitation occurs as it is located on the windward side of the Western Ghats. Heavy clouding and overcast condjtions exist during July and August. The cloud base is most often between $1000 \mathrm{ft}$ and $2000 \mathrm{ft}$ above sea level. Moderate to strong winds are present at the surface. The mean wind speed is between 10 and $15 \mathrm{~km} \mathrm{hr}^{-1}$. The average rainy days are about 70 in a year and receives about $200 \mathrm{~cm}$ rainfall.

\subsection{Poona}

Poona is situated on the lee-side of the Western Ghats. Winds are mostly westerly to southwesterly in the lower troposphere. The rainfall is low because it is in the rain-shadow region. Light continuous to intermittent rain occurs during the astive monsoon conditions from the stratocumulus and nimbostratus clouds. During the break monsoon conditions cumulus and occasionally cumulonimbus cloud development takes place. Maximum clouding takes place during the months of July and August. The cloud base is at 4000 to $5000 \mathrm{ft}$ above sea level. The mean wind speed is between 6 and $9 \mathrm{~km} \mathrm{hr}^{-1}$. Average rainy days are about 40 and receiaves bout $50 \mathrm{~cm}$ rainfall. 


\subsection{Rihand}

The region of measurements is in the catchment area of Rihand located in northeast India and is about $500 \mathrm{~km}$ from the coast. The area is in the zone of monsoon trough. Weak to moderate southerly to southwesterly winds prevail in the lower troposphere. The mean wind speed at the surface varies between 9 and $12 \mathrm{~km} \mathrm{hr}^{-1}$. Maximum clouding takes place during the months of July and August. The cloud base level is most often between $2000 \mathrm{ft}$ and $3000 \mathrm{ft}$. The average rainy days are about 40 and receives about $95 \mathrm{~cm}$ rainfall.

\section{Measurements and computations}

The number and types of clouds sampled at each place and the periocs of their sampling are given in table 1 . The aircraft flight altitudes corresponding to the average cloud base level were noted from the daily aircraft flights and compared with the corresponding computed cloud base heights (lifting condensation level) using the radiosonde data. The cloud diameters were estimated from the continuous recordings of the cloud liquid water content meter. The speed of the aircraft and the difference between the time of aircraft entry into the cloud and the time of exist were used for the evaluation of the cloud diameters.

The pressure at the cloud base, the height of the cloud base and the temperatures of the environment and the cloud-air at the cloud base level are given in table 2. The above information is based on the data obtained from the radiosonde observations.

Cloud liquid water content (LWC) was measured using a Johnson-Williams hot-wire device which measures the liquid water contributed by cloud drops of diameter $\leqslant 30 \mu \mathrm{m}$ (McCarthy 1974). The output of the LWC meter was amplified using an electronic circuit consisting of an operational amplifier (Burr-Brown

Table 1. Details of observations made in the Poona, Bombay and Rihand regions.

\begin{tabular}{|c|c|c|c|c|c|c|}
\hline $\begin{array}{c}\text { Place of } \\
\text { observation }\end{array}$ & $\begin{array}{l}\text { Geographic } \\
\text { co-ordinates }\end{array}$ & $\begin{array}{c}\text { Station } \\
\text { elevation } \\
\text { ASL } \\
\text { m }\end{array}$ & $\begin{array}{c}\text { Period of } \\
\text { observations }\end{array}$ & $\begin{array}{c}\text { Total } \\
\text { number } \\
\text { of days } \\
\text { of flights }\end{array}$ & $\begin{array}{c}\text { Total } \\
\text { number } \\
\text { of clouds } \\
\text { sampled }\end{array}$ & $\begin{array}{l}\text { Types of } \\
\text { clouds }\end{array}$ \\
\hline Poona & $\begin{array}{l}18^{\circ} 32^{\prime} \mathrm{N} \\
73^{\circ} 51^{\prime} \mathrm{E}\end{array}$ & 559 & $\begin{array}{l}\text { June-Sept. } \\
1973,1974 \text { and } \\
1976\end{array}$ & 61 & 2199 & $\mathrm{Cu}, \mathrm{Sc}$ \\
\hline Bombay & $\begin{array}{l}18^{\circ} 51^{\prime} \mathrm{N} \\
72^{\circ} 49^{\prime} \mathrm{E}\end{array}$ & 11 & Sept. 1974 & 7 & 169 & $\mathrm{Cu}$ \\
\hline Rihand & $\begin{array}{l}24^{\circ} 12^{\prime} \mathrm{N} \\
83^{\circ} 03^{\prime} \mathrm{E}\end{array}$ & 311 & Sept. 1974 & 2 & 104 & $\mathrm{Cu}, \mathrm{Sc}$ \\
\hline
\end{tabular}


USA, Model 3234/15 FET) and recorded on a direct writing 0-1 mA strip chart recorder (Easterline Angus, USA). The details of the electronic circuit used are shown in figure 1.

The temperatures of the cloud and cloud-free air were measured using a Weston make (USA) military disposal (vortex type) aircraft thermometer. The ascurasy of the thermometer was es.imated to be $\pm 0.5^{\circ} \mathrm{C}$ in the temperature range 0 to $40^{\circ} \mathrm{C}$ (from the calibration of the Air Company). The temperature sensor of the aircaft thermometer is provided with a suitable housing by the manufacturer and it is designed to prevent the sensor from wetting by direct contact with cloud and rain water. However in the present measurements, the error due to the wetting of the sensor $\mathbf{d}$ iring aircraft peneirations into the clouds and the subsequent lowering of temperatures due to the evaporation in clear air will be minimum since the environment during the monsoon season is nearly saturated with relative

Table 2. The mean values of cloud base (lifting condensation level) pressure and height, environmental and in-cloud temperatures at the cloud base level for the three places of observation. The maximum values of measured cloud liquid water content (JW-LWC) and computed adiabatic liquid water content $\left(\mathrm{W}_{a}\right)$ are also given.

\begin{tabular}{lcccccc}
\hline Place & $\begin{array}{c}\text { Cloud base } \\
\text { pressure } \\
(\mathrm{mb})\end{array}$ & $\begin{array}{c}\text { Cloud base } \\
\text { height } \\
(\mathrm{ASL})\end{array}$ & $\begin{array}{c}\text { In-cloud } \\
\text { temperature } \\
\text { at cloud } \\
\text { base } \\
(\mathrm{m})\end{array}$ & $\begin{array}{c}\text { Environmental } \\
\text { temperature } \\
\text { at cloud } \\
\text { base } \\
\left({ }^{\circ} \mathrm{C}\right)\end{array}$ & $\begin{array}{c}\text { Maximum } \\
\text { JW-LWC }\end{array}$ & $\begin{array}{c}\text { Adiabatic } \\
\text { LWC }\left(\mathrm{W}_{a}\right)\end{array}$ \\
\hline Poona & 892.3 & 1073 & 19.6 & 20.2 & 3.0 & 6.3 \\
Bombay & 975.5 & 255 & 23.3 & 24.3 & 1.5 & 8.4 \\
Rihand & 950.5 & 416 & 23.8 & 24.5 & 3.0 & 8.9 \\
\hline
\end{tabular}

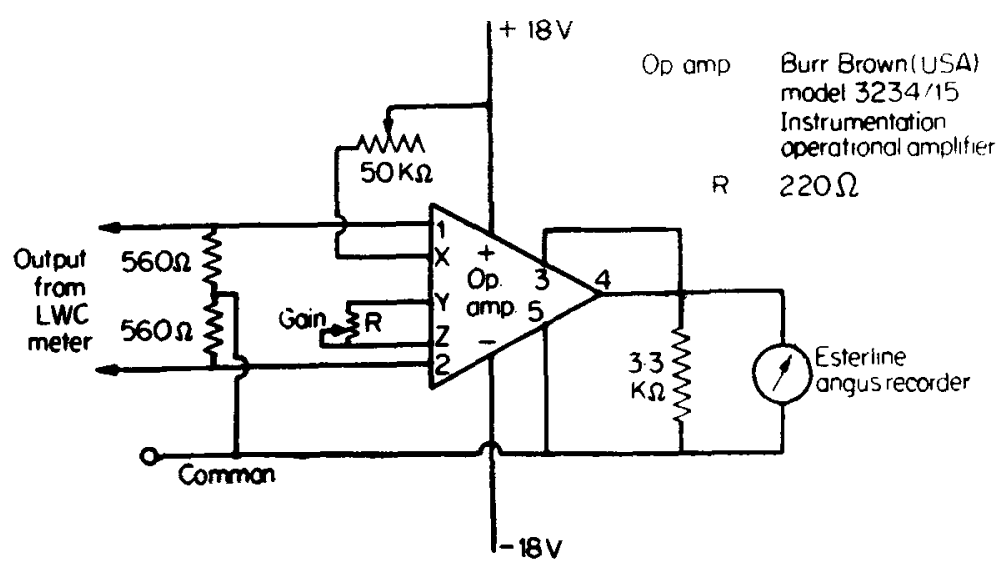

Figure 1. Electronic circuit used for the recording of cloud liquid water content (LWC). 
humidities exceeding $80 \%$ at all levels up to $10000 \mathrm{ft}$ above sea level. Also the observations indicated that on the average, the temperatures in the environment of the cloud (clear air) are warmer than the temperatures inside the cloud at all levels in the three regions of observation. In such conditions the error due to sensor wetting, if any, would be to underestimate the temperatures of the environment. Hence this will not change the results of the present study.

The aircraft temperatures were not corrected for compressive heating of the air due to aircraft speed (Ruskin and Scott 1974). However, sample computations were performed to understand the order of magnitude of the correstion. The maximum correction for the temperature difference between any two levels with an altitude differense of 500 feet was estimated to be within $\pm 0.15^{\circ} \mathrm{C}$. The above correction was estimated as follows :

For an average true air speed of 120 miles $\mathrm{hr}^{-1}$ the temperature correction is about $1.5^{\circ} \mathrm{C}$. The estimated percentage variations in the true air speed between any two levels is about $\pm 10 \%$. Hence the estimated correction to the temperature difference between any two levels is about $\pm 0 \cdot 15^{\circ} \mathrm{C}$. From the above it follows that the magnitude of correction is negligible since the speed of the DC-3 aircraft used for measurements is about 120 miles $\mathrm{hr}^{-1}$. Due to the above corroction the maximum erron in the dry ad:abatic and saturated adiabatic lapse rates is estimated to be within $\pm 10 \%$ and $\pm 20 \%$ respectively.

A comparison of the air raft and radiosonde temperatures was made using simultaneous observations made on a number of days. The maximum differen 0 between the temperatures obtained from aircraft and radiosonde at any level is within $\pm 0.5^{\circ} \mathrm{C}$. There is a very close agreement between the lapse rates obtained from the aircraft and radiosonde temperature data.

From the ahove considerations, the aircraft temperature data were used for the study of the thermodynamical aspects of monsoon clouds.

Also, another aircraft thermometer having continuous recording arrangement, designed and fabricated at the Institute, was flight-te ted on a few occasions during the above experiments. The details of the instrument were described elsewhere (Vernekar and Mohan 1975). The recordings of this instrument were not considered in the present study except for the data relating to a single cloud case shown in figure 9.

The cloud droplet size distrbituions were obtained using a spring loaded droplet sampler and magnesium oxide-coated glass slides. The details of the instrument were described elsewhere (Kapoor et al 1976).

Values of adiabatic liquid water content $\left(W_{a}\right)$ for different flight altitudes were computed using the radiosonde temperature data. It may be mentioned here that since the JW hot-wire meter is sensitive to cloud droplets of diameter $\leqslant 30 \mu \mathrm{m}$, as mentioned earlier, the measured values will not be representative of the total water content of the clouds. For the growth of cloud droplets below $30 \mu \mathrm{m}$ the condensation process is important. Hen se the JW-LWC data may be useful for evaluating the influence of the heat release 1 during the condensation of water vapour on the lapse rates of temperature inside the clouds.

Lapse rates of temperature inside the cloud and its immedia environment were computed using the temperature data obtained from the Western aircraft thermometer described above. 


\section{Results}

The observed and computed cloud hase heights and other thermodynamical parameters for Poona, Bombay and Rihand are given in table 3.

\subsection{Physical characteristics of clouds}

The vertical profiles of mean LWC, mean temperatures inside the cloud and its immediate environment for Poona, Bombay and Rihand are shown in figures 2, 3 and 4 respectively.

The standard deviations of the LWC and temperatures, shown in figures 2 to 4 , are respectively within $100 \%$ and $10 \%$ of their respective mean values for any of the altitude intervals. The maximum standard deviation for any altitude interval is within $150 \mathrm{ft}$. Hence the temperature at any level and in particular at the cloud base level did not differ greatly from day to day. Thus the average vertical profiles of tnmperatures above the sea level will be representative of the average vertical profile of temperature above cloud base level.

Table 3. Observed and computed cloud base heights and other parameters at Poona, Bombay and Rihand.

$\begin{array}{ccccc}\text { Period of observation } & \begin{array}{c}\text { Height of } \\ \text { LCL } \\ (\mathrm{m})\end{array} & \begin{array}{c}\text { Height of } \\ \text { observed } \\ \text { cloud base } \\ (\mathrm{m})\end{array} & \begin{array}{c}\text { Adiabatic } \\ \text { LWC for }\end{array} & \begin{array}{c}\text { Mean lapse rate }{ }^{\circ} \mathrm{C} / 100 \mathrm{~m} \\ \text { cloum height } \\ \left(\mathrm{gm} / \mathrm{m}^{3}\right)\end{array}\end{array}$

Poona

(July-September) 1012 1973

(July-September) 1974

(July-Səptember) 1976

(Average) 1973, 1974, 1976

(July) $1973,1974,1976$

(August) 1973, 1976

(Septomber) 1973,1976

Bombay

(September) 1974

Rikand

(September) 1974

980

1140

1078

1021

1027

1072

137
416

366
$-0.54$

655

$6 \cdot 37$

$-0 \cdot 50$

$-0.58$

1143

$5 \cdot 23$

$-0 \cdot 50$

$-0 \cdot 52$

655

$5 \cdot 89$

$-0.44$

$-0.56$

1006

$6 \cdot 30$

$-0.54$

$-0 \cdot 47$

1006

$5 \cdot 79$

$-0.41$

$-0 \cdot 51$

823

$7 \cdot 05$

$-0.54$

$-0.60$

$5 \cdot 89$

$-0 \cdot 61$

$-0.60$

686

$4 \cdot 33$

$-0.35$

$-0 \cdot 54$ 


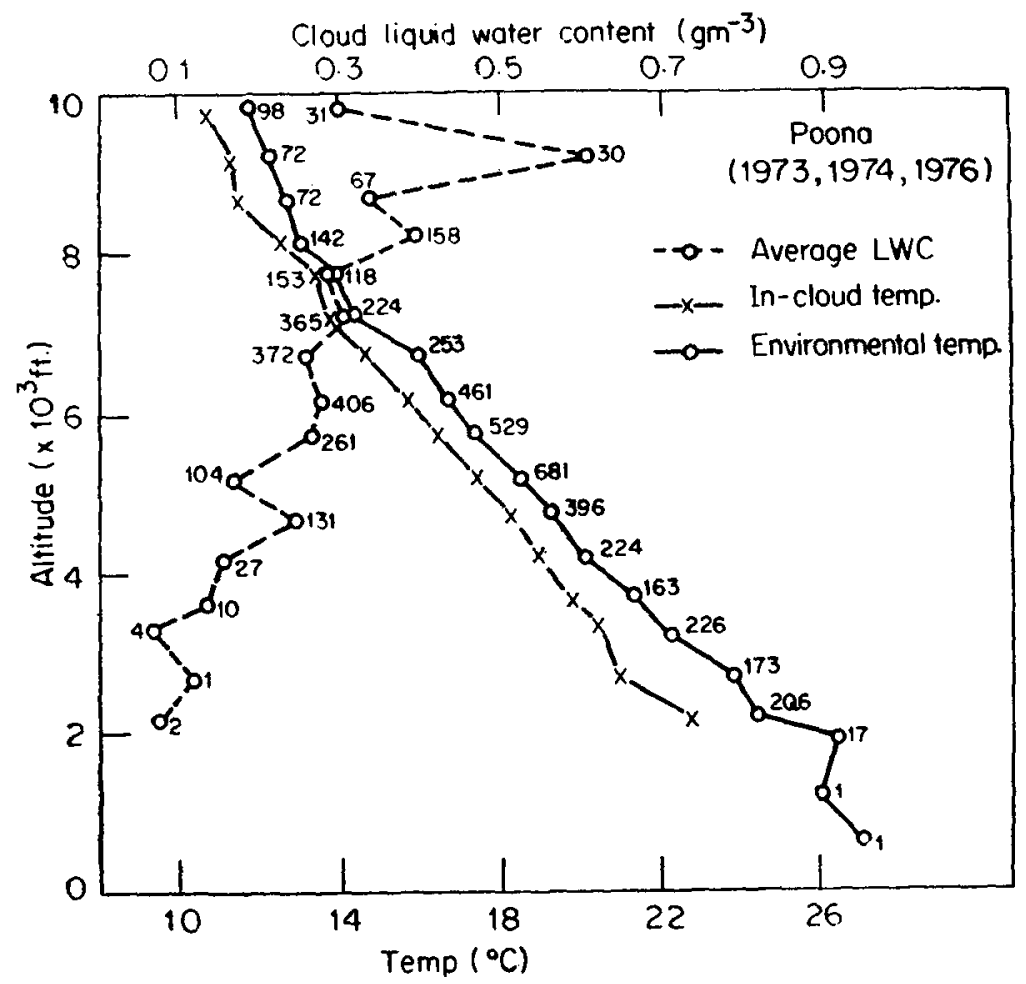

Figure 2. Vertical profiles of average cloud liquid water content (LWC), temperatures inside the cloud and its immediate environment for Poona. The figures indicate the number of observations.

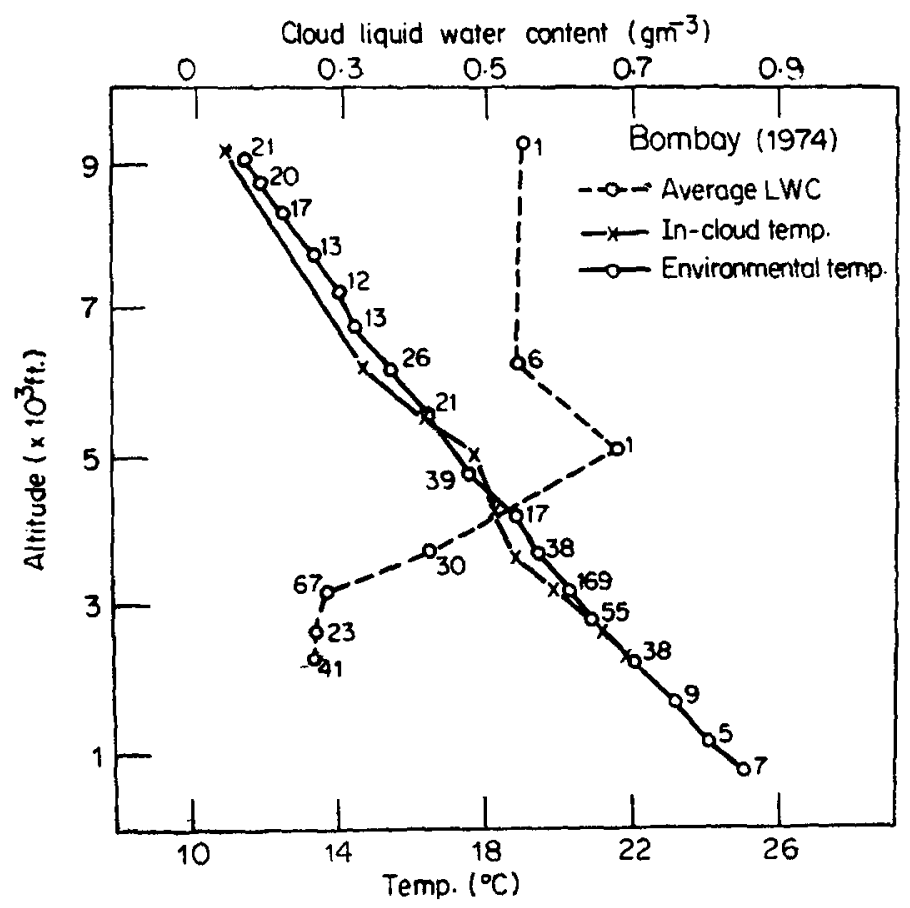

Figure 3. Same as figure 2 for Bombay. 


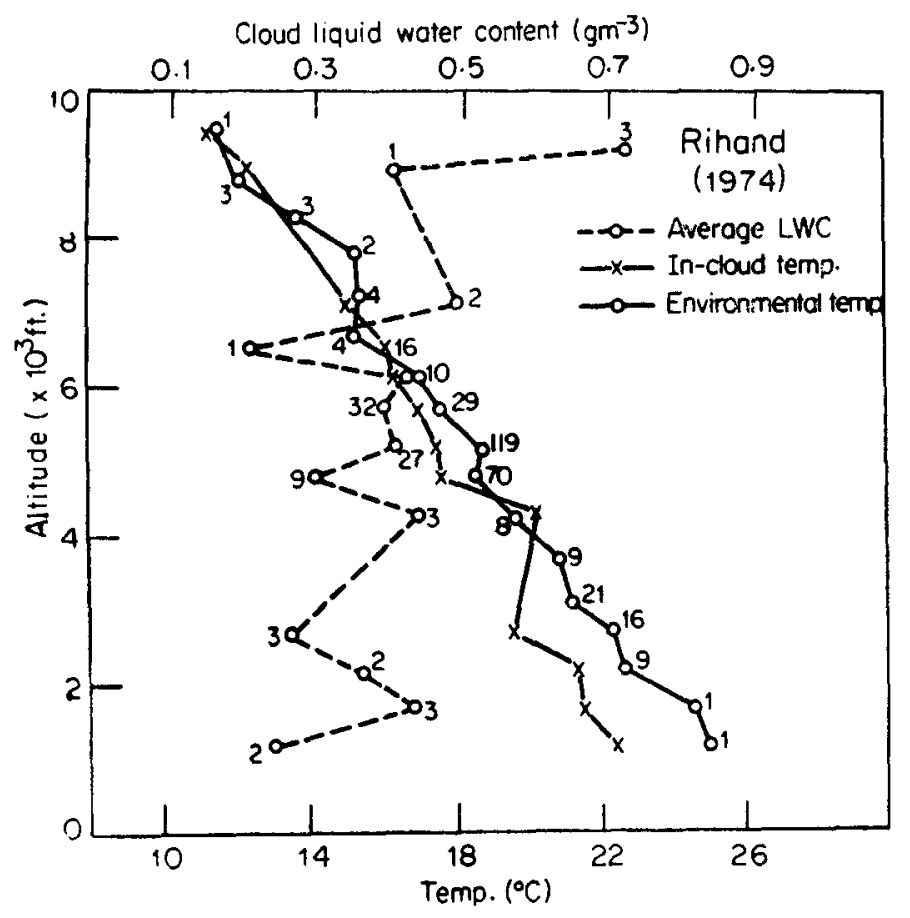

Figure 4. Same as figure 2 for Rihand.

The significance of the variations noticed in LWC and temperature from one altitude to another was evaluated using the $t$-test which is applicable for small samples (Siegel 1956). The mean, standard deviation and the number of observations for any two successive levels were utilised for computing the significance. It was noticed that most of the variations in $\mathrm{LWC}$ and temperature are significant at less than 5\% level for Poona. For Bombay and Ritand due to small sample size, the number of sign fi sant cases is less. The above results indicate that the lapse rates of $\mathrm{LWC}$ and temperatures are representative of the actual conditions.

At Poona the LWC showed a progressive increase up to $9000 \mathrm{ft}$ and thereafter decreased. At Bombay the LWC increased with height up to $5000 \mathrm{ft}$ and thereafter showed no marked variation. At Rihand the LWC is more or less uniform up to a heig $1 \mathrm{t}$ of $6500 \mathrm{ft}$ and thereafter increased. Thus the LWC profile at Rihand is distinctly different from those at Poona and Bombay.

\subsection{Temperature inside the cloud and its immediate environment}

At Poona, the temperatures inside the cloud at all levels are colder than its immediate environment. The temperature difference at the cloud base levels is as high as $2^{\circ} \mathrm{C}$. There is a tendency of narrowing of the temperature difference at higher levels.

At Bombay, the temperature difference between the cloud and its environment is not very marked as in the case of clouds at Poona. The maximum difference noticed is less than $1^{\circ} \mathrm{C}$ and it is negligible at the cloud base levels. Also the 
temperatures inside the cloud at $5000 \mathrm{ft}$ are warmer than those in its immediate environment. These features are different from those observed at Poona.

At Rihand the temperatures inside the cloud at most of the levels are colder than its environment as in the case of Poona. The maximum difference is as high as $3^{\circ} \mathrm{C}$ at the cloud base level. However, at 4500, 6500 and $9000 \mathrm{ft}$ levels, the temperatures inside the clouds are warmer than its environment.

The colder temperatures (aircraft) observed inside the cloud compared to its environment agree with the computed in-cloud and environmental (radiosonde) temperatures (table 2) at the cloud base level (lifing condensation level). The above result also agrees with that obtained from the extensive aircraft measurements made using Rosemount thermometer over the Arabian sea during MONEX-79. The data obtained during MONEX-79 also revealed that the temperatures in the cloud are colder than in its environment up to $10,000 \mathrm{ft}$ ASL (IMD, 1979).

4.3. Lapse rates of $L W C$ and temperatures inside the cloud and its immediate environment

The lapse rates of LWC and the lapse rates of temperature inside the clouds for Poona are shown in figure 5 as sample data. The lapse rates of temperatures inside the cloud and its immediate environment for Poona are shown in figure 6. Similar variations were noticed in the data obtained at Bombay and Rihand.

The significant variations in LWC and temperature from one to the successive higher level are marked in figures 5 and 6 . The results of the above statistical analysis confirm that the variations of $L W C$ in the vertical and the corres-

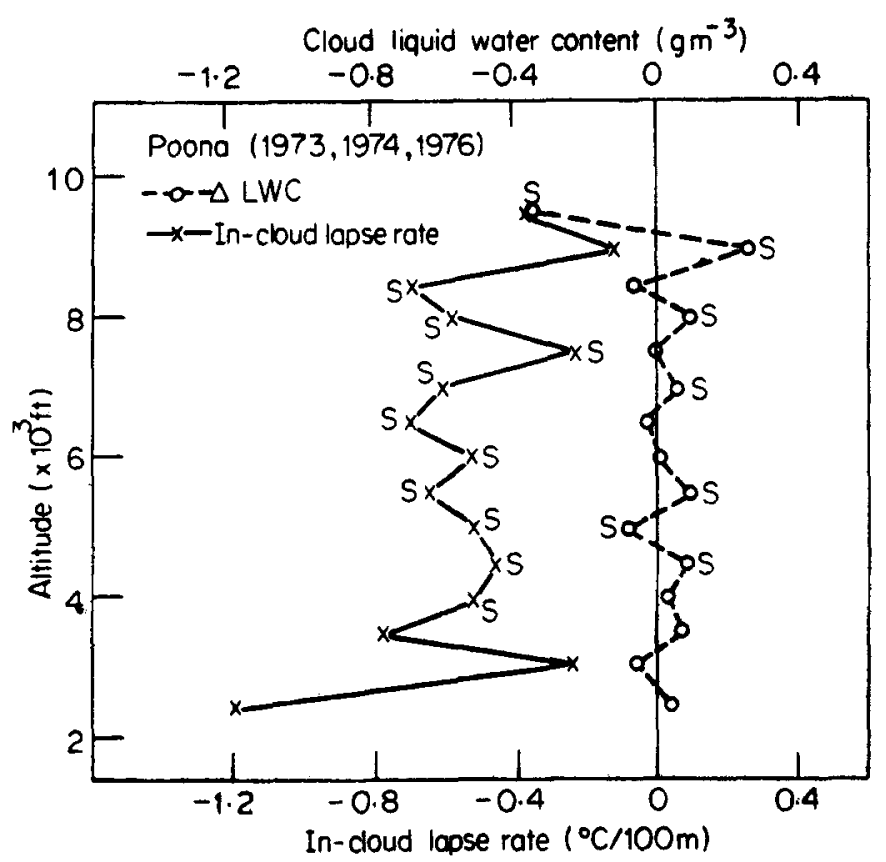

Figure 5. Vertical profiles of lapse rates of the cloud liquid water content (LWC) and temperature inside the cloud for Poona. ' $S$ ' indicates that lapse rates of LWC and temperature are significant at less than 5 per cent level. 


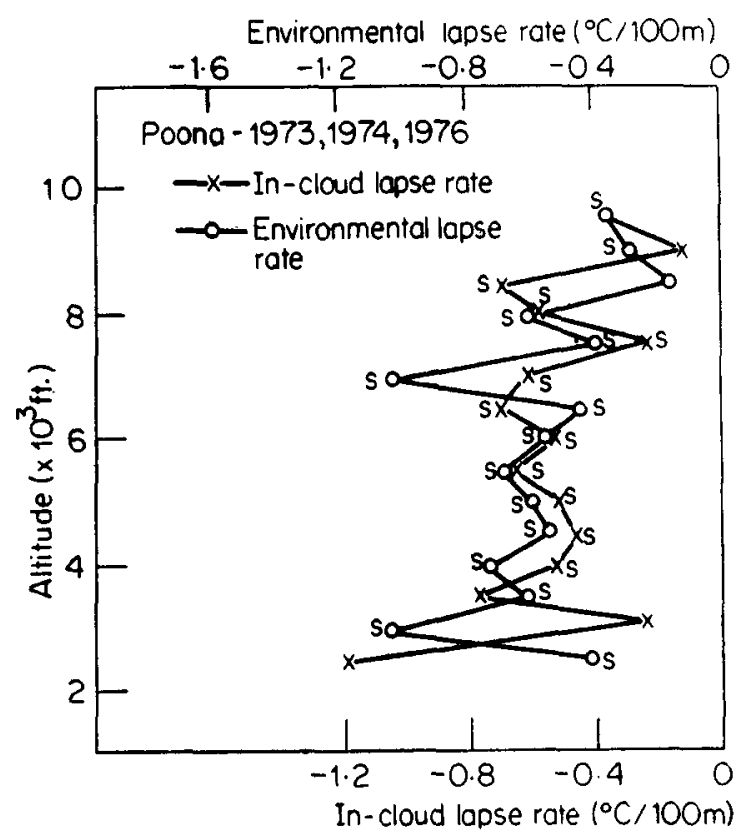

Figure 6. Vertical profiles of lapse rates of temperatures inside the cloud and its environment for Poona.

ponding variations of temperatures inside the cloud and its environment shown in figures 5 and 6 are real. Hence the results would be representative of the actual atmospheric conditions existing in the three regions during the monsoon season.

In general there appears to be some association between the lapse rates of LWC and temperature. The positive increments in LWC are associated with the positive increments in the temperatures inside the cloud. Similarly positive increments in temperature inside the cloud appear to be associated with the increments in temperature of its immediate environment at the same level or the laye immediately above. The lapse rates inside the cloud are slightly less than those in its immediate environment. The lapse rates in the environment are nearly equal to the saturated adiabatic value.

The steeper lapse rates in the environment compared to those inside the cloud may be attributed to (i) the latent heat released during the condensation of water vapour which would reduce the fall in temperature inside the cloud making the lapse rates less steeper and (ii) entrainment of warmer environmental air into the cloud. Since the environment is warmen than the cloud-air, the entrainment of environmental air into the cloud would give rise to increase in temperature inside the cloud and results in the decrease of the lapse rates. This anomalous result, derived from the measurements made for the first time in monsoon clouds in India does not agree with the results reported by others (Malkus 1952; Stommel 1947)'. The latter results are based on the abservations made in the environment which is colder than the cloud air. In the present case the environment is warmer than the cloud air. In view of the basic difference between the two cases the opposite result obtained in the present study appears to be consistent. 
Also, the investigations of others (Malkus 1952) relate to the clouds forming out of heated thermal bubbles. These bubbles ascend and grow due to the excess temperature of the cloud air over its environment. In all the cloud models, the cumulus clouds were likened to buoyant plumes, jets, or bubbles with internal circulations (Simpson 1976). In such clouds, entrainment of colder environmental dry air results in steeper temperature lapse rates.

In the case of monsoon cloud systems, cloud development takes place over vast areas due to forced lifting of air (Colon 1964; Miller and Keshava Murthy 1967; Bunker and Chaffee 1968). These clouds form in a nearly saturated environmental conditions. Forced lifting of air in a saturated environment gives rise to colder in-zloud temperatures at the cloud base levels as explained in $\S 5.1$. The current observations were undertaken for the first time in monsoon clouds and would be of value for the understanding of the monsoon systems from the cloud physics point of view. The anomalous result obtained in the present study should not be attributed to instrumental errors and the results might be of value for future investigations.

\subsection{Cloud drop size distributions}

The cloud drop size distributions for different altitudes for Poona and Bombay are shown in figures 7 and 8 respectively.

At Poona, the total droplet concentration varied between 28 and $82 \mathrm{~cm}^{-3}$. The concentration of bigger drops (diameter $\geqslant 50 \mu \mathrm{m}$ ) varied between 0.18 and $0.71 \mathrm{~cm}^{-3}$. The concentration of the bigger drops increased rapidly with height above the cloud base indicating that the size distribution experiences a broadening effect with increase in distance from the cloud base. The width of the drop size distribution increased progressively with height and it is maximum at $7000 \mathrm{ft}$.

At Bombay, the concentration varied between 28 and $75 \mathrm{~cm}^{-3}$. The concentration of the bigger drops (diameter $\geqslant 50 \mu \mathrm{m}$ ) varied between 0.05 to $0.74 \mathrm{~cm}^{-3}$.

The percentage contribution by the drops with diameter $\leqslant 30 \mu \mathrm{m}$ to the total LWC was computed using the data presented in figures 7 and 8 . It constitutes only $20 \%$ at Poona and $30 \%$ at Bombay to the total LWC. The computed LWC due to the drops of diameter $\leqslant 30 \mu \mathrm{m}$ is an order of magnitude less than that moasured by the JW-LWC meter. Hence it appears that the collection efficiency of the cloud droplet sampler (Kapoor et al 1976) may be low especially for the drops in the smaller size ranges. This is also seen from the very low concentrations of droplets. However, the drop size spectrum may be of some use for evaluating the collision-coalescence growth of cloud drops of diameter $>30 \mu \mathrm{m}$. The broadening of the drop size spectrum observed with height from the base of the cloud leads to the conclusion that the collision-coalescence growth is more effective at higher levels in the cloud. The JW-LWC also showed an increase with height from the base of the cloud. The collision coalescence process is a function of mean droplet size and the liquid water content (Johnson 1978). The clouds at the time of observation were in the non-raining stage. It is to be recagnised that the concentration of larger drops alone is not the only critical condition for rain initiation (Johnson 1978; Takahashi 1976).

The lower lapse rates observed inside the cloud compared to those observed in the environment of the cloud $(\S 4.3)$ is due to the heat of condensation of 


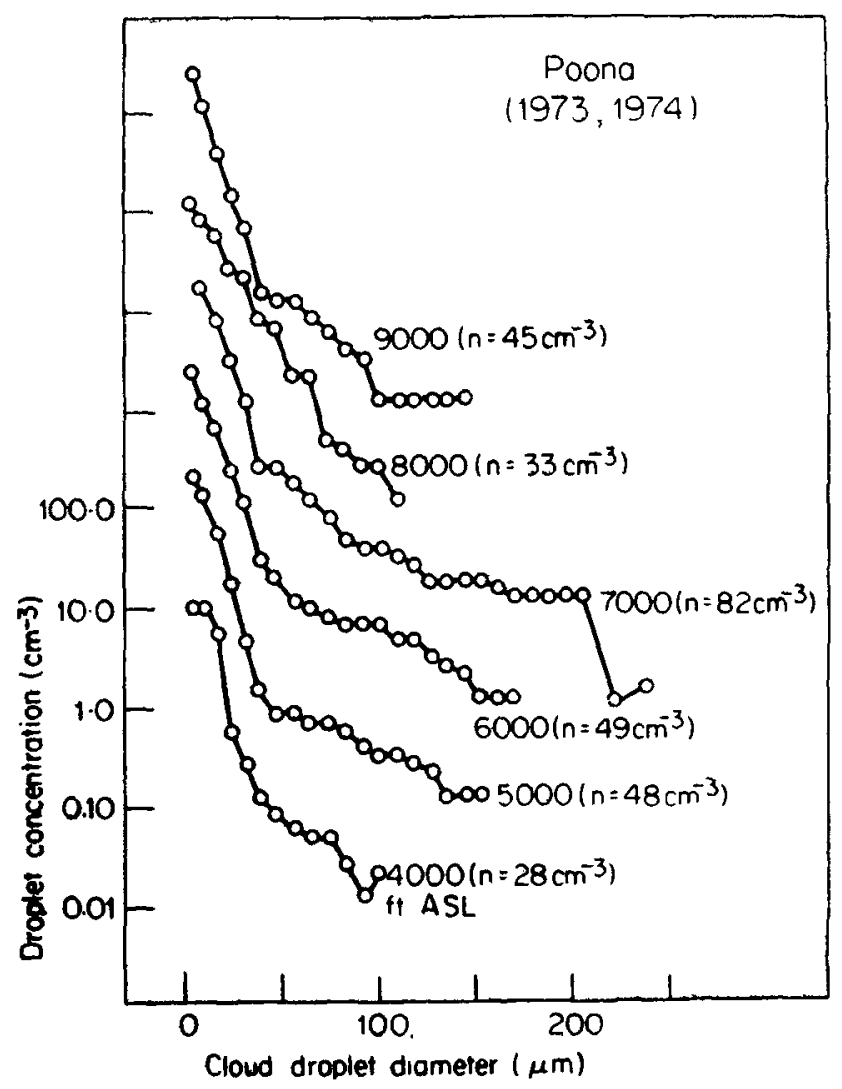

Figure 7. Cloud droplet size distributions at different aircraft altitudes for Poona. The ordinate scale is shifted by one order. The total concentration $(n)$ of the cloud droplets is also shown for each level.

water vapour. The increases in the JW-LWC could be taken as a measure of water condensed since the JW-meter measures the liquid water contributed by drops af diame:er $\leqslant 30 \mu \mathrm{m}$ which are generally formed by the condensation of wates vapour.

\section{Discussion}

The temperatures inside the cloud are in general colder than its immediate environment. The maximum difference in some cases at the cloud base lovel is up to $3^{\circ} \mathrm{C}$. The difference narrowed with height above the cloud base. One of the possible reasons for the observed colder in-cloud temperatures is discussed in the following.

\subsection{Colder in-cloud temperatures}

During the monsoon season the lapse rates in the environment are almost equivalent to saturated adiabatic value. When the air is lifted due to meso-scale 


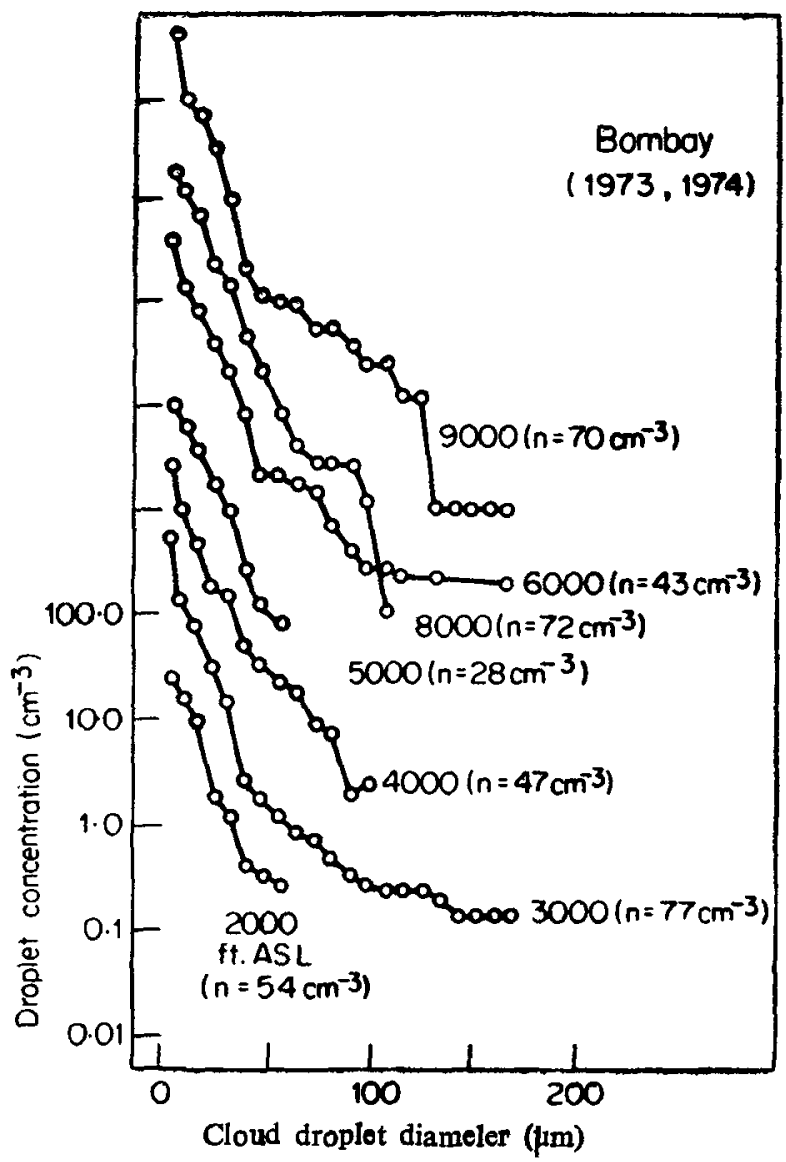

Figure 8. Same as figure 7 for Bombay.

convergence the parcel of air ascends following the dry adiabatic lapse rate til it reaches the lifting condensation lovel (cloud base level) and then follows the saturated adiabatic lapse rate. Hence it is expected that in-cloud temperatures at the cloud base levels are colder than those of its environment. The above hypothesis is further corraborated from the following. The in-cloud temperatures at the cloud base level (lifting condensation level) as computed from the radiosonde data are also found to be colder than the temperatures of the environment in majority of the cases (table 3). These resilts are consistent and agree with the temperature data recorded by the Weston aircraft thermometer.

The difference in the temperatures inside the cloud and its environment decreases with height and in some cases, at higher levels, the temperature inside the cloud becoming warmer than its environment. This could be due to the release of the latent heat of condensation inside the cloud. The abovo observation is consistent with the measurements made in warm tropical cumuli (Byers 1968; Cunningham and Glass 1965). Also, Wallace and Hobbs (1977) pointed out that the prevailing lapse rate in tropics is very nearly moist adiabatic so that the lifting of saturated air does not result in large temperature changes even when the rate of ascent is 


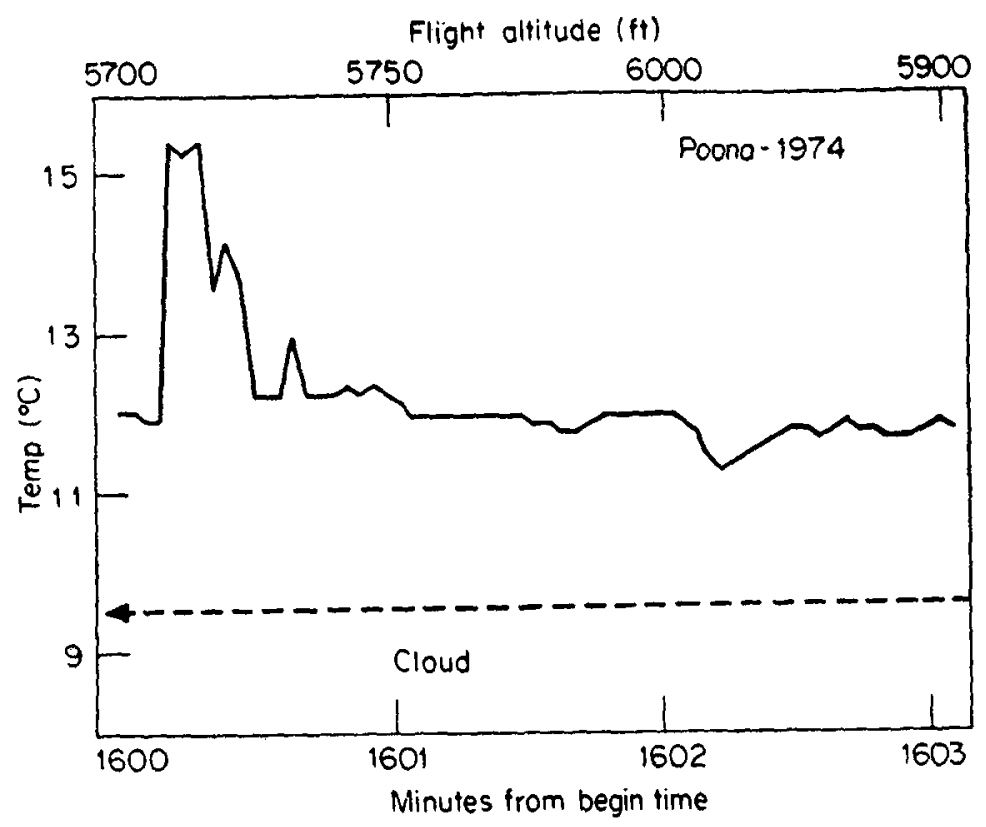

Figure 9. Temperature recording showing the horizontal cross-section obtained during aircraft penetration through an isolated cumulus cloud in the Poona region. The aircraft altitudes is also shown.

sufficiently large. It is seen from figures 5 and 6 that the positive increments in LWC give rise to positive increments in temperature, which may be attributed to the condensation of water vapour during the ascent of the air parcel and the release of latent heat of condensation. This feature suggests that the temperatures recorded inside the clouds and their immediate environment are reliable.

\subsection{Interaction between cloud and cloud-free air}

A close examination of the vertical profiles of the temperatures inside the cloud and its environment (figures 5 and 6) shows that the changes in the temperatures inside the cloud are seen refiected in the immediate environment of the cloud. This suggests that possible detrainment of cloud air into the immediate environment at any given altitude. From the above observations the structure of these clouds may be inferred to be made up of short thermals (bubbles) which ascend on one side and descend on the other. The ascent gives rise to candensation of water vapour. The latent heat released during the ascending thermal will partly be carried away to the immediate environment from the descending side of the thermal.

The above simple conception of the cloud model may be substantiated from the horizontal cross-section of the temperature structure inside the cloud shown in figure 9. 


\section{Conclusions}

A study of the thermodynamical and microphysical characteristics of monsoon clouds undertaken using extensive aircraft in-cloud observations made in several hundreds of clouds in the Poona, Bombay and Rihand regions suggested the following :

(i) The temperatures inside the cloud are colder than its immediate environment at Poona and Rihand. The maximum difference is about $3^{\circ} \mathrm{C}$ at the cloud base level and decreased with height from the base of the cloud. At Bombay the difference is less than $1^{\circ} \mathrm{C}$ and at some levels the in-cloud temperatures are warmer than the environment.

(ii) The lapse rates of temperature inside the cloud are slightly less than those in the immediate environment of the clouds. The lapse rate of temperature in the environment is, in general, nearly equal to the saturated adiabatic value.

(iii) There appears to be some association between the lapse rates of cloud liquid water content (LWC) and the temperature. The positive increments in LWC are assaciated with positive increments in temperature inside the cloud. Similarly the positive increments in temperature inside the cloud are associated with the increments in temperature of its immediate environment at the same level or the layer immediately above. This observation suggests the possible detrainment of the cloud air into its immediate environment. These clouds may consist of short thermals (bubbles) which ascend on one side and descend on the other. The ascent gives rise to condensation of water vapour and the latent heat released will be partially carried away to the immediate environment from the descending side of the thermal. The above hypothesis is also corroborated from the horizontal cross section of temperature structure inside clouds.

(iv) The LWC profile showed an increase with height from the base of the cloud both at Poona and Bombay. There are no marked valiations of $L W C$ with height at Rihand.

(v) The total cloud droplet concentration at different altitudes at Poona and Bombay are in the range $28-82 \mathrm{~cm}^{-3}$. The size distribution of cloud droplets experienced a broadening effect with increase in distance from the cloud base at Poona. The broadening effect at Bombay is not as marked as that at Poona.

\section{References}

Bunker A F and Chaffee M 1968 Tropical Indian Ocean Clouds (Honolulu, University of Hawaii : East-West Press) pp. 193

Byers H R 1968 Proc. Int. Conf. Cloud Physics, August 1968, University of Toranto, Canada pp. 544

Colon A J 1964 Indian J. Meteorol. Geophys. 15182

Cunningham R M and Glass 1965 Proc. Int. Conf. Clouds Physics May 1965, Tokyo and Sapporo (Japan: Japan Meteorological society) p. 109

India Meteorological Department (IMD) 1979 First GARP global experiment MONEX data set 2.3. Aircraft data (flight level) AVRO, pp. 46

Johnson B D 1978 Proc. Conference on Cloud Physics and Atmospheric Electricity, American Meteorological Society, July-August 1978, Issaquah, Washington, USA, pp. 31

Kapoor R K, Paul S K, Murthy A S R, Krishna K and Ramana Murthy Bh V 1976 Pure Appl. Geophys. 1976114379 
Malkus J S 1952 Tellus 471

McCarthy J S 1974 J. Atmos. Sci. 311028

Millor F R and Keshava Murthy R N 1967 Structure of an Arabian sea summer monsoon system, (Honolulu, University of Hawaii; East-West Press) pp 94

Ruskin A E and Scott W D 1974 in Weather and climate modification, ed, W N Hess (New York : John Wiley) pp. 842

Siegel S 1956 Non-parametric statistics for the behavioural sciences (New York : McGraw-Hill) Simpson J 1976 Advances in geophysics (New York : Academic Press) 1972

Stommel H $1947 J$. Meteorol. 491

Takahashi T 1976 J. Atmos. Sci. 33 p. 269

Vernekar K G and Mohan B 1975 Indian J. Meteorol. Hydrol. Geophys. 26253

Wallace J M and Hobbs P V 1973 Atmospheric science : an introductory survey (New York: Academic Press Inc.) pp. 467

Warner J 1969 J. Atmos. Sci. 261049

Warner J 1970 J. Atmos. Sci. 27682

Warner J 1973 J. Atmos. Sci. 30256 